\title{
DO INVESTIGATIONS OF COMPETITION AUTHORITIES REALLY INCREASE THE DEGREE OF COMPETITION? AN ANSWER FROM TURKISH CEMENT MARKET
}

\author{
Aydin Çelen, Burak Günalp*
}

\begin{abstract}
:
In this paper, we assess the effects of the investigations carried by the Turkish Competition Board in 1997, 2002 and 2003 on the degree competition in the Turkish cement market. For this aim, we used proverbial Bresnahan-Lau framework with alternative definitions for the supply relation. Our first finding is that cement producers had a considerable amount of market power at the period prior to the first investigation in 1997. In addition, this study shows that, parallel to our initial expectation, competition in the cement market increased thanks to the investigations. The positive effect of the first investigation is found to be especially significant. Hence, this study witnesses that the enforcement of the competition law by the Turkish Competition Board has produced the desired effects in the most problematic sector with respect to competition law.
\end{abstract}

Keywords: market power, market performance, cement market, Bresnahan-Lau methodology, degree of competition, competition policy

JEL Classification: D43; L13; L40; L61

\section{Introduction}

Facilities of cement producers are the most favored playgrounds for competition authorities around the world. The reason for this has been explained clearly by Whish (2001), who argued that: "The first thing I say to the students is, every system of competition law will deal with cartels and the first thing for any new competition regulator is to go out and find the cement cartel. Because my experience of this subject is, it is always there, somewhere. The only countries in which I had been unable to find the cement cartel is where there is a national state-owned monopoly for cement." This claim may seem to be too exaggerated at the first glance; however, it defines exactly what we have experienced in Turkey since the beginning of the application of the competition law.

Aydin Çelen, Turkish Competition Authority, 06800 Bilkent, Ankara, Turkey (acelen@rekabet.gov.tr); Burak Günalp, Hacettepe University, Department of Economics, 06800 Beytepe, Ankara, Turkey (gunalp@hacettepe.edu.tr). 
Although the Turkish Competition Act was adopted in 1994, the authority responsible for applying it was formed in 1997. The cement market has always been under the supervision of Turkish Competition Board. Through more than ten years, the Board has investigated the cement market several times and imposed considerable amount of fines to cement producers breaching Competition Act.

Our goal in this paper is to evaluate the effects of the investigations carried by the Competition Board on the degree of competition in the cement market. For this aim, we used a model suggested by Bresnahan (1982) and Lau (1982), which are accepted as the root of the "New Empirical Industrial Organisation" (NEIO). Our initial expectation is surely that competition in the cement market would increase thanks to the investigations. However, Kulaksizoglu (2004) having similar motives to ours concluded that the introduction of competition policy has not made the cement industry more competitive despite all the investigations and fines.

The paper is organized as follows: The next section gives some information regarding the antitrust investigations on cement market in Turkey and the European Union (EU). Relevant literature about both measuring the effects of investigations on competition and applications of Bresnahan-Lau model are presented in Section 3. Section 4 provides the theoretical background of the Bresnahan-Lau methodology. The description of the data used in this study is presented in Section 5. Section 6 is devoted to the empirical results of the model. And finally, Section 7 discusses the findings, and concludes.

\section{Cement Market in Turkey and in the EU}

In Turkey, the Competition Act was adopted in 1994. The purpose of the Act is to prevent agreements, decisions and practices which restrain, distort or restrict competition in markets for goods and services, as well as abuse of dominant position by dominant firms in the market.

Although adopted in 1994, the Turkish Competition Act started to be applied in 1997 with the formation of the authority responsible for enforcing it. The first investigation of the Turkish Competition Authority was unsurprisingly on the cement market. At the end of raids and long investigations, the Competition Board announced its decision on 17 June, 1999, and concluded that five firms in the Aegean Region of Turkey infringed the competition law by determining their sales collectively and sharing the relevant geographic market among themselves. The total fine imposed against 5 firms was approximately 2.1 million euros. All firms went to the State Council to appeal the decision.

On 17 June, 1999, at the same day of imposing fines to cement producers from the west part of Turkey, the Competition Board also kicked off the second investigation on the rest of the country, namely on the Central Anatolia, Marmara and Mediterranean regions. In February 2002, the Competition Board found 18 cement producers out of 22 guilty of price fixing and market sharing. The total fine applied amounted to 4.1 million euros.

In February 2003, the Competition Board initiated another investigation on the cement producers from Aegean Region of Turkey. The parties were the same as those of the first investigation. At the end of the investigation in December 2004 finding producers guilty of price fixing, the Board fined them 7.9 million euros approximately. 
Similar to most of the Competition Board decisions imposing fines at the end of an investigation, these three decisions related with the cement market failed to escape from the reversion of the State Council. The Competition Board renewed these decisions in the recent years. All parties in these investigations went to the court to appeal the new decisions, and the cases are still pending.

Cement industry is always the subject of the investigations of Competition Authorities in the European Union (EU), even for its new member countries from Central and Eastern Europe.

In 1994, the European Commission fined 42 companies for dividing the cement market among themselves and sharing information. In 2000, the European Union court reduced their total fines from 248 million euros to 108 million euros.

In one of the largest corporate fines ever handed out in Europe, the German Competition Authority also fined six cement companies 660 million euros in 2003 for collusive behavior in terms of setting production quotas for the members of the cartel. The main reason for such a harsh sanction was the fact that the illegal conduct covered a time period of at least ten years.

Cement sector has still continued to attract the attention of EU trustbusters. In November 2008 and September 2009, the European Commission raided the offices of several major European cement companies on suspicion of cartel activities. The investigations of the European Commission seem to be continued.

Among Central and Eastern European countries, the Polish Office of Competition and Consumer Protection (OCCP) and the Romanian Competition Council are the authorities which imposed considerable amount of fines on cement producers. In December 2009, the Polish OCCP has levied the highest fine (99 million euros) in its 20 years history against seven cement producers. In 2005, three cement companies controlling 98 percent of Romania's cement market were fined 27 million euros by the Romanian Competition Council.

\section{Relevant Literature}

\subsection{Studies Measuring the Effects of Antitrust Investigations on Competition and Prices}

It is generally accepted that cartels do not reduce costs and serve only to raise prices. If this is true, then antitrust investigations carried by competition authorities would inevitably reduce prices. On the other hand, it is also possible that as a result of antitrust prosecution the market became more transparent and in turn created more suitable environment to collude during or following investigation. Since both cases are theoretically possible, several empirical studies have aimed at finding an answer to the question whether antitrust enforcement and investigations lead to increased competition and lower prices in specific markets.

Most of the studies that have addressed this question have reached the startling conclusion that antitrust enforcement does not lead to lower prices.

Stigler and Kindahl (1970) studied nine industries accused for price fixing between 1959-1964, and concluded that the prices in only two industries fell appreciably after a case was brought. 
Newmark (1988) looked at the price of bread in Seattle and found that an antitrust indictment had nearly no effect on the price. In 1964-66, the retail price of bread in Seattle declined relative to the US average price. This event has often been associated with the prosecution of Bakers of Washington. However, Newmark (1988) found that the reason for diminishing average bread price is not ceased collusion but several inexpensive, lower-quality brands of bread began selling in Seattle during 1964-66.

Similarly, Feinberg (1980) and Choi and Philippatos (1983) found that negative effect of indictments on profitability is very small.

Sproul (1993) examined the effects of antitrust prosecution on prices charged by firms indicted for price fixing in 25 cases filed between 1973-1984. The average prices were found to gradually rise by about 7 percent over the 4 years following an indictment leading to the conclusion that the antitrust activity is doing more harm than good.

Unlike these studies, there are other studies examining the general effects of the introduction of a competition law in a country rather than specific investigations on competition and prices in markets. Symeonidis (2002) examined the effects of the introduction of 1956 Restrictive Trade Practices Act in the UK on prices and market structures. He found that with the abolition of restrictive practices across a wide range of industries the firms chose to merge, thus concentration in all industries increased. It is also shown that the legislation had a negative effect on profitability of previously collusive industries at the beginning, but subsequent restructuring of industries helped firms to recover their profit margins. It means that the profitability was found to be unchanged significantly with the introduction of competition law in UK.

Similarly, Konings et al. (2001) investigated whether the new competition law introduced in 1993 led to a decline in the price mark-up in Belgium. The results show that competition policy in Belgium did not have an effect on price-cost margins, which suggests that the old price regulatory system and strong import competition already disciplined firms in a substantial way.

\subsection{The Applications of Bresnahan-Lau Model}

The Bresnahan-Lau methodology has been employed by numerous studies to identify the degree of competition in general, or market power of a firm in particular in a variety of industries.

Buschena and Perloff (1991) investigated whether the legal and institutional changes in the early 1970s allowed the Philippines to be a dominant firm in the coconut oil export market. They generalized Bresnahan's (1982) model, allowing the oligopoly conduct parameter to vary over time with the legal and institutional changes in the Philippines, and using a dominant firm and competitive fringe model to estimate oligopoly power in the Philippine coconut oil export industry. They found that especially the creation of the Philippine coconut oil refining and exporting agency allowed the Philippine coconut oil export industry to start exercising a substantial amount of its potential dominant firm market power.

Shaffer (1993) applied the Bresnahan-Lau methodology to banking sector. $\mathrm{He}$ used data from 1965 to 1989 to test the market power in Canadian banking and found that the banking behavior was consistent with perfect competition over this period. 
Results showed a slight, though statistically significant, increase in competition after 1980, at which time revisions were made to the Bank Act. With these revisions, the degree of competition shifted unexpectedly from a competitive state to what Shaffer calls a "supercompetitive" state where marginal cost exceeds marginal revenue.

Deodhar and Sheldon (1997) used the Bresnahan-Lau model to estimate the degree of imperfect competition in the world market for soymeal exports, accounting for entry of Argentinean firms into the export market using a technique similar to Buschena and Perloff. They found the world market for soymeal exports to be perfectly competitive, even prior to entry by Argentinean firms in the mid-1970s.

Çelen (2003) also applied the Bresnahan-Lau model to the UK tea market, and concluded that the market functioned "supercompetitively" during the period between 1990-2001.

Zeidan and Resende (2009) used a flexible dynamic econometric formulation of the Bresnahan-Lau methodology to measure market power in the Brazilian cement industry. Their results confirmed their expectation, indicating that the conduct parameters were higher in the Northern region, where only one firm operates. In the Southeast region, where the majority of firms operate, all conduct parameters were indicative of a smaller degree of market power as compared to the other regions.

Bask et al. (2009) examined how the degree of market power has changed as the Nordic power market has evolved from national markets to a multinational market. The results showed that suppliers of electricity have had some market power during this integration period, but that the degree of market power has been reduced as the market has expanded.

To the best of our knowledge, Kulaksizoğlu (2004) is the only study employing the Bresnahan-Lau model specifically to examine the effects of the antitrust indictments on the degree of competition in a market. Similar to ours, Kulaksizoğlu (2004) selected Turkish cement market for the application of this model.

\section{Theoretical Framework}

In determining the effects of the investigations of Competition Board on the degree of competition in the cement market, the well-known Bresnahan-Lau model was used.

In the Bresnahan-Lau model, the buyers are accepted as price-takers and the market price and quantity are determined by the intersection of demand and supply equations. The (inverse) demand equation may be as follows:

$$
Q=D(P, Z ; \alpha)+\varepsilon
$$

where $Q$ is quantity, $P$ is price, $Z$ is a vector of exogenous variables affecting demand, e.g. the price of a substitute or income, $\alpha$ is a vector containing the parameters of the demand system to be estimated, and $\varepsilon$ is the econometric error term. ${ }^{1}$

The structure of the second equation defining supply-side relationships varies depending on the intensive of the competition in the market at hand. When the market is perfectly competitive and the sellers are price-takers, price equals marginal cost, and the relationship can be written easily as follows:

1 The most basic demand equation may be with only one exogenous variable: $\mathrm{Q}=\alpha_{0}+\alpha_{P} P+\alpha_{Z} Z+\varepsilon$. 


$$
P=M C(Q, W ; \beta)+\eta
$$

where $W$ are exogenous variables on the supply-side, e.g. input prices, $\beta$ the supplyfunction parameters, and $\eta$ the supply error. $M C(\cdot)$ represents the marginal cost.

However, when the market is not perfectly competitive, we can talk about a supply relation, rather than a supply function. Accordingly, perceived marginal revenue, not price, is equal to marginal cost. This, in general, takes the form

$$
P=M C(Q, W ; \beta)-\lambda \cdot h(Q, Z ; \alpha)+\eta
$$

where $P+h(\cdot)$ is marginal revenue, $P+\lambda \cdot h(\cdot)$ is marginal revenue as perceived by the firm. The demand-side parameters and exogenous variables, namely $(Q, Z$ and $\alpha)$ are included into $h(\cdot)$ because they affect marginal revenue. ${ }^{2}$ At the one extreme point, when $\lambda=0$ the market is perfectly competitive, and thus marginal cost equals marginal revenue. On the other side, when $\lambda=1$, there exists the situation of a perfect cartel in which market power reaches its maximum level, and intermediate $\lambda \mathrm{s}$ correspond to other oligopoly situations. ${ }^{3}$

In effort to determine whether investigations carried on the Turkish cement market in 1997, 2000 and 2003 affect the degree of competition in this market, we defined three different models by using three dummy variables for the investigations of Competition Board, namely $D 1997, D 2000$ and $D 2003$. The dummy variable $D 1997$ takes the value 1 from December 1997 (the month just after first investigation's initiation) on, D2000 takes the value 1 from March 2000 (the month just after second investigation's initiation) $)^{4}$ on and D2003 takes the value 1 from March 2003 (the month just after third investigation's initiation). Model 1 is the most basic one in which the parameter measuring the degree of competition is defined as $\lambda=\lambda_{0}+\lambda_{1}$ D1997. In Model 2, the relevant parameter takes the form $\lambda=\lambda_{0}+\lambda_{1}$ D1997 $+\lambda_{2}$ D2000. Finally, in Model 3, the formula $\lambda=\lambda_{0}+\lambda_{1}$ D1997 $+\lambda_{2}$ D2000 $+\lambda_{3}$ D2000 is used. To be precise, in Model $3, \lambda_{0}$ is the degree of competition before December 1997, $\lambda_{0}+\lambda_{1}$ is the measure for the period between December 1997 and March 2000, $\lambda_{0}+\lambda_{1}+\lambda_{2}$ is the measure for the period between March 2000 and March 2003 and $\lambda_{0}+\lambda_{1}+\lambda_{2}+\lambda_{3}$ is for the period between March 2003 and December 2004.

At the first glance, it may seem that it would be a trivial task to determine $\lambda$ by solving equations 1 and 2a simultaneously. However, the situations of competition and cartel are not distinguishable from each other in such a system of equations unless the demand function does not fulfill some necessities explained below. Following

2 In order to find the exact value of $h(\cdot)$, it is enough to solve the profit maximisation problem: $\underset{Q}{\max } \pi=Q \cdot D^{-1}(Q)-C(Q)$. The first order condition is $D^{-1}(Q)+Q \cdot\left(\frac{\partial D^{-1}(Q)}{\partial Q}\right)-M C(\cdot)=0$. Since the firm receives a fraction $\lambda$ of the profit depending on the intensity of competition in the market, the general representation is $P=M C(\cdot)-\lambda \cdot Q \cdot\left(\frac{\partial D^{-1}(Q)}{\partial Q}\right)$, so $h(\cdot)$ equals $Q\left(\frac{\partial D^{-1}(Q)}{\partial Q}\right)$.

3 For example, Cournot equilibrium has $\lambda=1 / n$ where $n$ is the number of sellers in the market.

4 Although the decision of the second investigation was taken on 17 June 1999, the investigation started effectively on 17 February 2000 with the entrustment of the experts. 
Bresnahan's (1982) study, it is possible to show the nature of the problem in identifying the market power parameter, $\lambda$.

To make explanations clearer, let us take the simplest linear versions of both demand and supply equations. The demand equation is

$$
Q=\alpha_{0}+\alpha_{P} P+\alpha_{Z} Z+\varepsilon
$$

and the marginal cost function is $M C=\beta_{0}+\beta_{Q} Q+\beta_{W} W$. Then, according to the condition $P=M C-\lambda \cdot h()+\eta$, the supply relation turns out to be as follows:

$$
\mathrm{P}=\beta_{0}+\beta_{Q} Q+\beta_{W} W-\lambda\left(Q / \alpha_{P}\right)+\eta
$$

In such a model, the demand equation is identified no matter which form the supply relation takes. The demand equation (3) has only one included endogenous variable, $P$, and there is an excluded exogenous variable, $W$, so the equation is identified. In a similar way, supply relation (4) is also identified. For the supply relation, there exists one included endogenous variable, $Q$, and one excluded exogenous variable, $Z$.

However, the market power parameter, $\lambda$, cannot be determined in such a system. In order to see this problem, supply relation (4) can be rewritten as follows:

$$
P=\beta_{0}+\gamma Q+\beta_{W} W+\eta
$$

where $\gamma=\beta_{Q}-\lambda / \alpha_{P}$. In this system, it is possible to estimate the parameter of variable $Q$, namely $\gamma$, which is dependent on $\beta_{Q}, \lambda$ and $\alpha_{P}$ Although $\alpha_{P}$ is known due to demand function, the other two parameters, $\beta_{Q}$ and $\lambda$, cannot be determined separately. In other words, we cannot know whether we are tracing out $P=M C$ or $M R=M C$, and the market power parameter can take any value between 0 and 1 .

\section{Figure 1}

Parallel Shift of the Demand Curve $-\lambda$ not identified

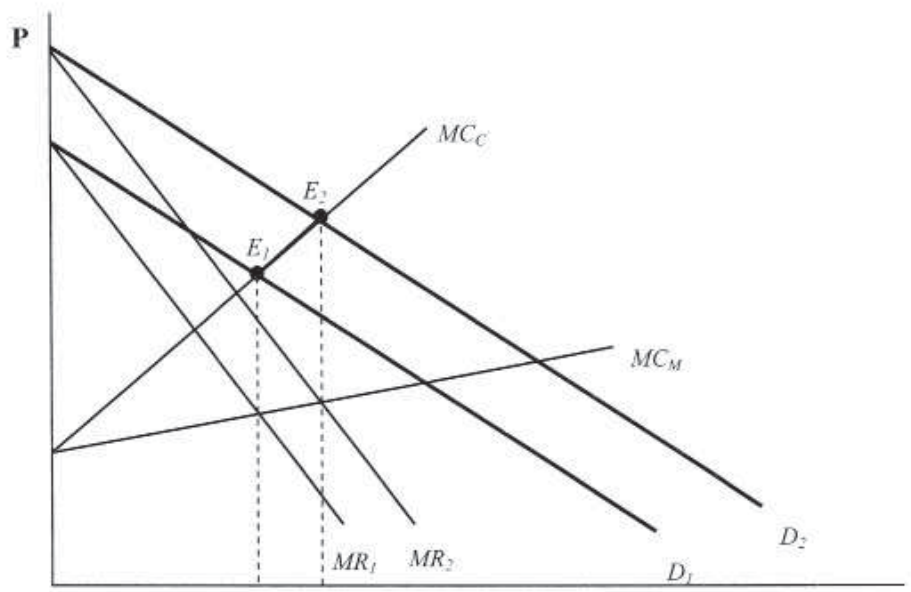

Source: Bresnahan (1982). 
Following Bresnahan (1982), the problem in measuring the competitiveness of such a market may be explained more clearly by the help of a figure (Figure 1). The researcher observes the market price and quantity in the initial equilibrium, $E_{l}$. The researcher also estimates the demand line, $D_{l}$, and thus can infer the marginal revenue line, $M R_{I}{ }^{5}{ }^{5}$ But the costs cannot be observed directly. Since, the observed equilibrium, $E_{l}$, is consistent with both a competitive market structure and a perfect cartel, the researcher cannot tell anything about the degree of the competition in the market. In respect of a competitive structure, the equilibrium, $E_{l}$, is determined by the intersection of $M C_{C}$ and $D_{l}$, where $M C_{C}$ is the marginal cost curve. The equilibrium, $E_{l}$, may be also a result of a cartelised market structure with a lower marginal cost curve, $M C_{M}$. In this case, the equilibrium, $E_{l}$, is determined by the intersection of $M C_{M}$ and $M R_{l}$. Now assume an increase in $Z$ (for example in income) which shifts the demand curve out to $D_{2}$. This new equilibrium, $E_{2}$, is still consistent with either of the two marginal cost curves. In other words, prices and quantities in this new equilibrium may be the outcome of either perfect cartel or perfect competition. In fact, $M C_{C}$ is the supply relation either for the competitor for whom $M C_{C}$ is marginal cost, or for the cartel with lower, flatter marginal cost, $M C_{M}$. Unless the marginal costs are known, the researcher cannot determine from this shift in $Z$ whether the market is competitive or cartelised.

Bresnahan (1982) solved the problem of identifying $\lambda$ by adding an exogenous variable to demand function which not only shifts its intercept up and down but also rotates it. In other words, an exogenous variable capable of changing the slope of the demand function may help to determine the parameter of the market power, $\lambda$. Bresnahan (1982) illustrated graphically the intuition of this argument as follows (Figure 2).

Figure 2

Rotation of the Demand Curve $-\lambda$ identified

$P$

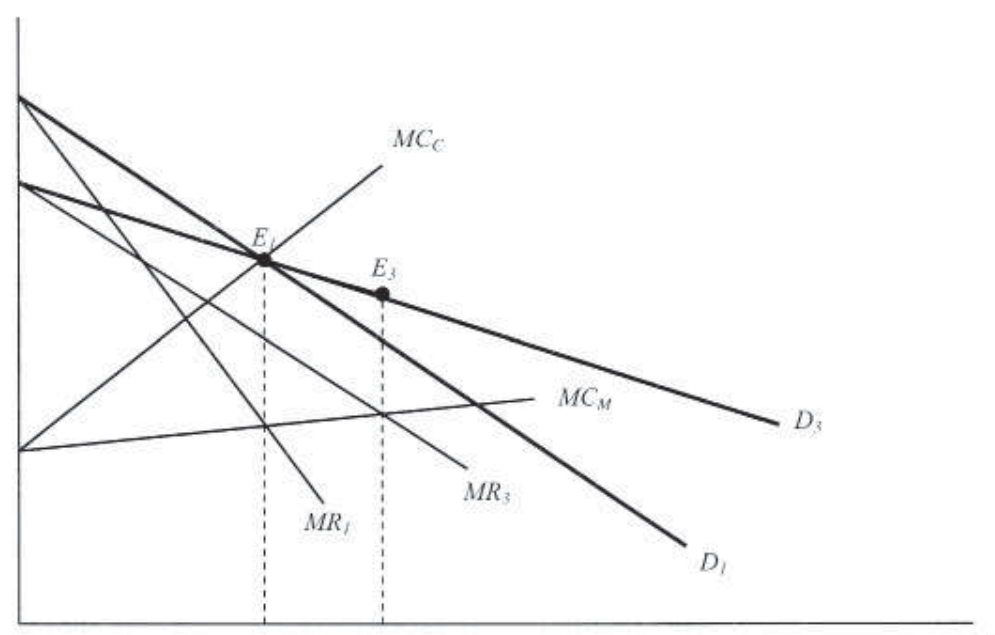

Source: Bresnahan (1982).

5 Since the demand curve is assumed to be linear, MR is also linear and twice as steep. 
In Figure 2, the demand curve and the two cost curves, $M C_{C}$ and $M C_{M}$, are the same as before. But now, instead of shifting up vertically, the demand curve is rotated around $E_{1}$ and the new demand curve, $D_{3}$, is obtained. ${ }^{6}$ If the relevant marginal cost curve is $M C_{C}$ and the market is perfectly competitive, then the rotation of the demand curve will not have any effect on the equilibrium, and the initial equilibrium, $E_{l}$, will continue to be equilibrium under new demand conditions, $D_{3}$. However, if the market is perfectly cartelised and the marginal cost curve is $M C_{M}$, then the equilibrium shifts to such a point $\left(E_{3}\right)$ that $M C_{M}$ equals to $M R_{3}$. Thus, according to whether or not the equilibrium shifts, the researcher may infer the competitiveness of the market.

In Bresnahan's (1982) model, the variable which rotates demand curve and thus helps to identify the market power parameter is an interaction term between variables $P$ and $Z$. So the demand equation (3) in the simple example has been altered to

$$
Q=\alpha_{0}+\alpha_{p P}+\alpha_{z Z}+\alpha_{P Z} P Z+\varepsilon
$$

where $P Z$ is the interaction variable between variables $P$ and $Z$. Accordingly, the supply relation turns out to be the following structure:

$$
P=\beta_{0}+\beta_{Q} Q+\beta_{W} W-\lambda\left(Q / \alpha_{P}+\alpha_{P Z} Z\right)+\eta
$$

Since only one exogenous variable $(P Z)$ is included into the demand equation, the demand equation (3a) is still identified. ${ }^{7}$ Thus, the parameters $\alpha_{P}$ and $\alpha_{P Z}$ can be considered as known while dealing with the supply relation. As for the supply relation (4a),

there are two included endogenous variables, $Q$ and $Q^{*}$, where $Q^{*}=-Q /\left(\alpha_{P}+\alpha_{P Z} Z\right)$ and there are two excluded exogenous variables, $Z$ and $P Z$. Thus, the supply relation is identified, and the market power parameter, $\lambda$, can be determined as the coefficient of $Q^{*}$.

The conditions under which the movements of exogenous variables can rotate the demand curve have been established by a companion paper of Lau (1982). According to the so-called impossibility theorem of Lau (1982), virtually any functional form for the demand curve leads to identification except two most commonly used forms: linear and log-linear. Hence, in order to measure the market power parameter, one must add an interaction term (like suggested by Bresnahan (1982)), a squared term or something else that leads to non-linearity and allows the demand curve to rotate. In the literature, several variables have been used as the rotation variable: Suominen (1991) and Shaffer (1993) include income in addition to the interaction term between price and substitute price. In Buschena and Perloff (1991), two time trends are used as rotation variables.

\section{Data Description}

We are concerned with the cement market for the period between January 1994 and December 2004. The reason for stopping in December 2004 is that the source of data

6 Here the demand curve is rotated around the original equilibrium point only for graphical simplicity. It is, of course, also possible to observe both rotation and vertical shift together.

7 For the demand equation (3a), there exist one included endogenous variable, $P$, and one excluded exogenous variable, $W$. 
on cement price, the Turkish Statistical Institute (TURKSTAT), changed its way of collecting price data at the beginning of 2005 causing a significant jump in the price series. For this reason, for each variable 132 monthly observations have been used, which is enough to make statistically meaningful predictions.

The quantity $(Q)$ of the cement sold in Turkey is one of the endogenous variables of the model. The data on this variable were obtained from the Turkish Cement Manufacturers' Association (TCMA). The other endogenous variable is the cement price $(P)$. Although cement is generally known as a homogeneous commodity, actually it has several variations. In this study, we formed a composite price by averaging the prices of portland and mixed portland cement with respect to their shares in the relevant month. The prices of portland and mixed portland cement are collected from the TURKSTAT as stated above while their shares are obtained from the TCMA.

It would be reasonable to use the price of a rival as the rotation variable in the demand equation. However, this is not the case for cement because there is no rival to cement. This is to say that cement has been substituted to very limited extent by other commodities, such as steel, wood or asphalt. Given that the cement is generally consumed in the constructions, construction permits taken from municipalities may be a driving force of the cement demand. Also, since most of the buildings are sold by using a loan, it may be logical to expect that home loan rates may affect the cement demand, at least indirectly. ${ }^{8}$ But, it is certainly true that the effects of these two variables on the cement demand will not be immediate, but dispersed over months. Thus, 6-month moving averages of these two variables were used as rotation variables in the demand equation in this study. The data on construction permits, denoted by $C$, are provided by the TURKSTAT, and the data on minimum level of home loan rates $(R)$ came from the Central Bank of the Republic of Turkey.

As for the supply relation, equation (4a), there are several cost items which are candidates for the exogenous variables. The most crucial inputs in the cement production are electric, coal (Lignite, Pit Coal), and craft paper. Among them, electric and Pit Coal are adopted in this study since they constitute the major part of total costs. The prices of these cost items, illustrated by $E$ and $M$ respectively, were obtained from the TURKSTAT.

As explained above, the dummy variables $D 1997, D 2000$ and $D 2003$ were defined to determine whether three investigations carried on the Turkish cement market in 1997, 2000 and 2003 affected the degree of competition in this market.

Meanwhile, to capture the obvious seasonality in the cement consumption, three dummies, $D S P, D S U$, and $D F A$, were introduced in the demand equation. ${ }^{9}$

All nominal values collected from the TURKSTAT were deflated using the Producer Price Index (PPI). Statistical properties of the variables used in the study are presented in Table 1.

8 To be more precise, the housing and cement demand is mostly affected by ex ante (expected) real interest rate, namely nominal interest rate minus expected inflation rate. However, we had to use the nominal interest rates mainly because of the fact that the inflation expectation survey carried out by the Central Bank of the Republic of Turkey does not cover the most of the time period we studied. In addition, since the change in the nominal interest rate is a good reflection of the economic conditions and psychological situation for investment in a country, we are of the opinion that the nominal interest rate is one of the driving factors of the cement demand, which is confirmed by the results of the estimation in the following pages.

9 The dummy variable for Winter is the reference season, and hence excluded from the regression. 
Table 1

Descriptive Statistics of Main Variables $(n=132)$

\begin{tabular}{|l|l|r|r|}
\hline Variable & \multicolumn{1}{|c|}{ Description } & \multicolumn{1}{c|}{ Mean } & \multicolumn{1}{c|}{ Std.Err. } \\
\hline $\boldsymbol{Q}$ & Quantity of Cement & $2,497,487$ & $760,606.2$ \\
\hline $\boldsymbol{P}$ & Real Price of Cement & 13.50 & 1.44 \\
\hline $\boldsymbol{E}$ & Real Price of Electricity & 22.71 & 2.56 \\
\hline $\boldsymbol{M}$ & Real Price of Pit Coal & $14,024.36$ & $2,403.03$ \\
\hline $\boldsymbol{C}$ & Floor Area of Buildings Given Construction Permits & $5,635,755$ & $1,605,373$ \\
\hline $\boldsymbol{R}$ & Home Loan Rate & 65.12 & 21.84 \\
\hline $\boldsymbol{D 1 9 9 7}$ & Dummy Variable for the First Investigation & 0.64 & 0.48 \\
\hline $\boldsymbol{D 2 0 0 0}$ & Dummy Variable for the Second Investigation & 0.44 & 0.49 \\
\hline $\boldsymbol{D 2 0 0 3}$ & Dummy Variable for the Third Investigation & 0.17 & 0.37 \\
\hline $\boldsymbol{D S P}$ & Dummy Variable for the Spring Months (March, April, May) & 0.25 & 0.43 \\
\hline $\boldsymbol{D S U}$ & $\begin{array}{l}\text { Dummy Variable for the Summer Months (June, July, } \\
\text { August) }\end{array}$ & 0.25 & 0.43 \\
\hline $\boldsymbol{D F A}$ & $\begin{array}{l}\text { Dummy Variable for the Fall Months (September, October, } \\
\text { November) }\end{array}$ & 0.25 & 0.43 \\
\hline
\end{tabular}

Source: TCMA, TURKSTAT and Central Bank of the Republic of Turkey

\section{Empirical Analysis}

As a starting point to the analysis, it may be logical firstly to examine the evolution of the price and quantity of cement sold during the period we studied. To this end, we plotted the price and quantity of cement during this period (Figure 3). We also marked the starting date of three investigations on the figure.

Figure 3

The Evolution of the Price and the Quantity of Cement

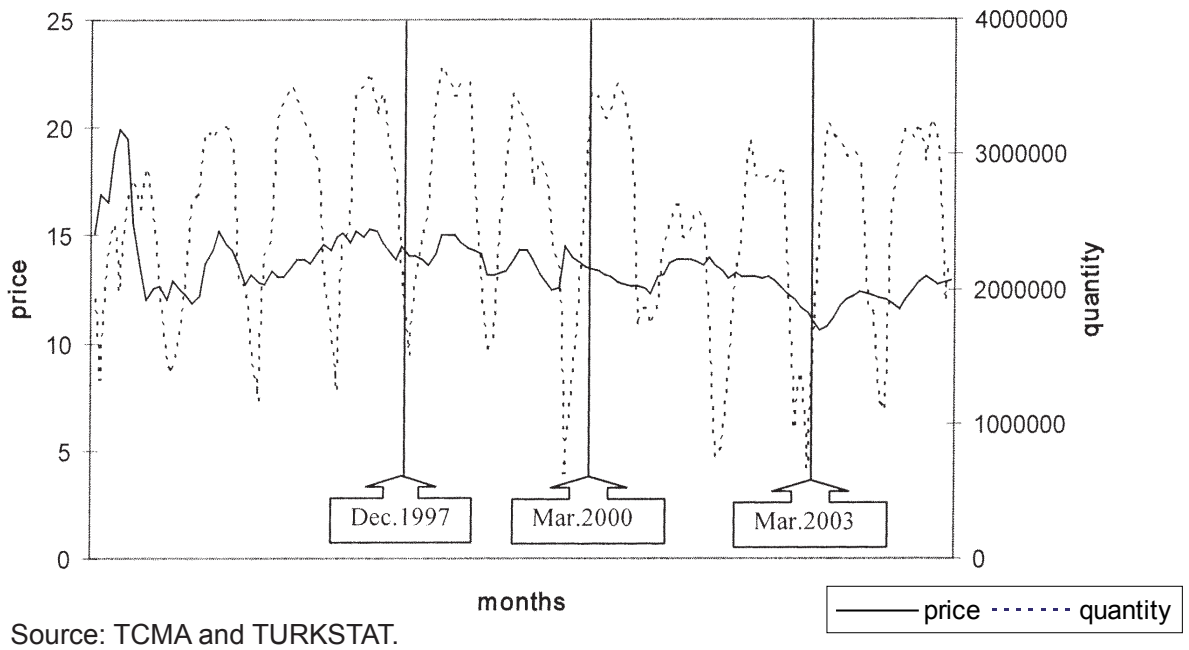


The most obvious observation from the figure is that there exists a clear seasonality in the quantity of cement sold. The price of the cement fluctuated mildly during the time under investigation. From the figure, we cannot observe clear impact of three competition investigations on the price and quantity of the cement. ${ }^{10}$ Thus, inspecting the price and quantity plot of the cement can not shed light on three investigations' effects if any.

\subsection{Preliminary Tests}

Our initial concern is to determine whether the variables used in determining if three cement investigations started by the Turkish Competition Board has increased competition in the market are stationary or not. For this aim, we used Augmented Dickey Fuller (ADF) test.

The ADF test for stationarity of a time series, $X_{t}$, begins with the estimation of the following regression equation:

$$
\Delta X_{t}=\alpha+\beta t+\gamma X_{t-1}+\sum_{i=1}^{p} \delta_{i} \Delta X_{t-i}+\varepsilon_{t}
$$

where $t$ is a linear time trend which is used to represent a possible deterministic trend, $\alpha$ is the parameter of a likely drift and $\varepsilon_{t}$ is a random residual term. In addition, lagged first differenced dependent variables, $\Delta X_{t-i}$, are included to consider the autocorrelated omitted variables. The ADF test can be summarised shortly as follows: If $\gamma=0$, then the series is said to have a unit root and is nonstationary. In contrast, if the hypothesis of $\gamma=0$ is rejected, it can be concluded that the time series does not have a unit root and is integrated of order zero (stationary).

Meanwhile, first of all, the appropriate lag length, $p$, should be determined. For this aim, we started with minimum number of lagged first differenced variables, namely 0 , and then, if necessary, increased it gradually until the residuals turned out to be white noise. In order to see whether in each step the residuals are white noise or not, we applied the Ljung-Box Q-test to residuals.

The results of the Ljung-Box Q-test suggest for all variables, except $E$, that lagged first differenced variables are needed to induce a white-noise residual. The number of lagged first differences, namely $p$, needed ranges from zero to five, as seen in the second column of Table 2 .

Having determined the number of the lagged first differenced variables in the ADF regression equation (6), the $\mathrm{ADF}$ regression test was conducted for each variable. The results of the integration order (stationarity) test are summarised in Table 2. The results show that the null hypothesis of unit root can be rejected for variables $Q, P$ and $C$ at the $1 \%$ significance level, and for variables $M$ and $R$ at the $10 \%$ significance level. It means that these variables are stationary. In contrast, the variable $E$ was found nonstationary under all meaningful significance levels.

10 When we deseasonalized the quantity of cement by using method of dummy variables, we still witnessed no clear impact of the investigations on the deseasonalized quantity (not reported here). 
Table 2

Augmented Dickey-Fuller Test for Integration Order (stationarity)

\begin{tabular}{|l|l|c|c|c|}
\hline \multicolumn{2}{|l|}{ Variables } & Lag $(p)$ & $\begin{array}{c}\text { Computed } \\
\text { Statistic }\end{array}$ & Critical Value \\
\hline$Q$ & Quantity of Cement & 2 & -7.458 & $-4.030^{*}$ \\
\hline$P$ & Real Price of Cement & 1 & -4.795 & $-4.030^{*}$ \\
\hline$E$ & Real Price of Electricity & 0 & -1.343 & $-3.146^{* *}$ \\
\hline$\Delta E$ & First Difference of Real Price of Electricity & 0 & -10.617 & $-4.030^{*}$ \\
\hline$M$ & Real Price of Pit Coal & 4 & -3.186 & $-3.146^{* *}$ \\
\hline$C$ & $\begin{array}{l}\text { Floor Area of Buildings Given Construction } \\
\text { Permits }\end{array}$ & 5 & -4.464 & $-4.031^{*}$ \\
\hline$R$ & Home Loan Rate & 3 & -3.246 & $-3.146^{* *}$ \\
\hline
\end{tabular}

* The critical value of the $1 \%$ significance level.

** The critical value of the $10 \%$ significance level.

Source: authors' computations according to equation (6).

Since the variable $E$ is nonstationary in its level, we took its first difference and applied ADF test to the first differenced variable. ${ }^{11}$ The results reveal that the null hypothesis of unit root in the first differenced variable $(\Delta E)$ can be rejected at the $1 \%$ significance level. To sum up, it is confirmed that the variable $E$ is nonstationary and integrated of order one, I(1), because the first difference of this variable is stationary. Since the electricity is the most important cost item in the cement production, ${ }^{12}$ we prefer not to exclude it from our analysis.

\subsection{Empirical Model and Results}

To estimate the likely impact of investigations on the competition in the cement market, two variables, floor area of buildings given construction permits $(C)$ and minimum of home loan rate applied by Turkish banks $(R)$, have been used to make MR curve rotate. Hence, the demand function is given by

$$
Q_{t}=\alpha_{0}+\alpha_{P} P_{t}+\alpha_{C} C_{t}+\alpha_{R} R_{t}+\alpha_{P C} P C_{t}+\alpha_{P R} P R_{t}+\varepsilon_{t} .
$$

In the second equation, namely in the supply relation, two cost items, real price of electricity $(E)$ and real price of pit coal $(M)$, have been used as explanatory variables. Accordingly the supply relation is specified as

$$
P_{t}=\beta_{0}+\beta_{Q} Q_{t}+\beta_{E} E_{t}+\beta_{M} M_{t}+\lambda Q_{t}^{*}+\eta_{t}
$$

where $Q_{t}^{*}=-Q_{t} /\left(\alpha_{P}+\alpha_{P C} P C_{t}+\alpha_{P R} P R_{t}\right)$

11 But before, in order to determine the number of the lagged first differenced variables, we applied Ljung-Box Q-test to first differenced variable. It has been found that no lagged first difference variable is needed for first differenced $\mathrm{E}(\Delta \mathrm{E})$.

12 According to SPO (2008), the share of electricity in total cement costs is $23.5 \%$. 
In a model consisting of a system of equations, like in our current model, the simultaneity problem may occur when some of the endogenous variables are located at the right hand side of the equations. Turning to our model, the endogenous variable $P$ is the explanatory variable for the demand function (7), while other endogenous variable, $Q$, is the explanatory variable for the supply relation (8). Since the application of OLS to this model yields biased and inconsistent estimates, the demand function (7) and supply relation (8) were estimated using an instrumental variable technique, Two Stage Least Squares (2SLS). In the first stage of 2SLS, instruments used to estimate endogenous variables should be defined. The exogenous variables in a model can serve as instruments. Thus, real price of electricity $(E)$ and real price of pit coal $(M)$ are selected as instruments for the demand equation (7), while floor area of buildings given construction permits $(C)$, minimum of home loan rate $(R)$ and seasonal dummies are the instruments for the supply relation (8).

The estimation results for the demand equation (7) and the supply relation (8) are reported in Table 3 and Table 4, respectively.

As seen in Table 3, the $R^{2}$ of the demand equation is 0.672 . This implies that the model specification fits the data quite well. As the results suggest, all variables are statistically significant at the 5\% significance level. Since the demand equation includes interaction terms, $P C$ and $P R$, the coefficients of the variables cannot be interpreted directly. However, following some computations, it is possible to obtain the own-price elasticity of cement, the elasticity of cement demand with respect to floor area of buildings given construction permits $(C)$ and to home loan rate $(R)$.

Table 3

2SLS Regression Estimates for Demand Equation (7)

\begin{tabular}{|l|r|r|}
\hline Parameter & Estimate & p-value \\
\hline Intercept $\left(\alpha_{0}\right)$ & $1.27 \mathrm{e}+7(5262378)$ & 0.017 \\
\hline Real price of cement $\left(\alpha_{P}\right)$ & $-930803.7(415094.2)$ & 0.027 \\
\hline Floor area of buildings given construction permits $\left(\alpha_{C}\right)$ & $0.708(0.308)$ & 0.023 \\
\hline Home loan rate $\left(\alpha_{R}\right)$ & $-210214.4(64171.72)$ & 0.001 \\
\hline Real price of cement * floor area of buildings $\left(\alpha_{P C}\right)$ & $-0.045(0.023)$ & 0.056 \\
\hline Real price of cement * home loan rate $\left(\alpha_{P R}\right)$ & $16199.46(5008.224)$ & 0.002 \\
\hline Dummy Variable for the Spring Months (DSP) & $1174900(113920.4)$ & 0.000 \\
\hline Dummy Variable for the Summer Months (DSU) & $1681640(122493.2)$ & 0.000 \\
\hline Dummy Variable for the Fall Months (DFA) & $1342175(112146.2)$ & 0.000 \\
\hline R $^{2}$ & 0.672 & \\
\hline
\end{tabular}

Note: Standard errors in parentheses.

Source: authors' computations according to equation (7).

The own-price elasticity of cement $\left(\varepsilon_{Q P}=\frac{\partial Q(P)}{\partial P} \cdot \frac{P}{Q(P)}\right)$, evaluated at the 
sample means of variables (presented in Table 1), is estimated to be -0.7 , indicating a downward sloping demand curve for the cement. ${ }^{13}$ The elasticity of cement demand with respect to floor area of buildings given construction permits $\left(\varepsilon_{Q C}=\frac{\partial Q(C)}{\partial C} \cdot \frac{C}{Q(C)}\right)$, on the other hand, is calculated to be $0.228 .{ }^{14}$ This implies that the quantity of the cement demanded $(Q)$ increases by approximately 0.23 per cent in response to a 1 per cent increase in the floor area of buildings given construction permits $(C)$.

In a similar fashion, the elasticity of cement demand with respect to home loan rate $\left(\varepsilon_{Q R}=\frac{\partial Q(R)}{\partial R} \cdot \frac{R}{Q(R)}\right)$ is found to be $0.217 .{ }^{15}$ This means that the quantity of the cement demanded $(Q)$ increases by approximately 0.22 per cent in response to a 1 per cent increase in the home loan rates $(R)$.

The 2SLS estimates for the supply relations of three alternative models are presented in Table 4 . The results suggest that the explanation power of the regression for the supply relations is also quite well. In all three models, most of the coefficients are statistically significant at the $5 \%$ significance level while the coefficient of real price of electricity is significant at a level slightly larger than $10 \%$. Also all the coefficients have positive signs in all three models, as expected.

Among the parameters estimated, the $\lambda$ s are important in respect of determining the likely impact of investigations on the competition in the cement market. The results of the alternative models are found to be very robust against alternative $\lambda$ definitions. As for the period prior to the first investigation carried out in 1997, the relevant parameter $\left(\lambda_{0}\right)$ is found between 0 and 1 as expected, and significantly different from zero, in all three models. This is to say that we can clearly reject the hypothesis that the cement market was perfectly competitive and all producers acted as price takers prior to first investigation.

The parameter $\lambda_{1}$ gives us the impact of the first investigation on the competition in the cement market. It is found negative and significantly different from zero in all three models, meaning that the first investigation increased the competition in the cement market, and made it approach toward perfect competition.

$$
\begin{aligned}
\hline 13 \quad & \varepsilon_{Q P}=\frac{\partial Q(P)}{\partial P} \cdot \frac{P}{Q(P)}=\left(\alpha_{P}+\alpha_{P C} \bar{C}+\alpha_{P R} \bar{R}\right) \cdot\left(\frac{\bar{P}}{\overline{Q(P)}}\right) \\
& =(-9330803.7-0.045 * 5635755+16199.46 * 65.121) *(13.494 / 2497487)=-0.7 \\
14 \quad & \varepsilon_{Q C}=\frac{\partial Q(C)}{\partial C} \cdot \frac{C}{Q(C)}=\left(\alpha_{C}+\alpha_{P C} \bar{P}\right) \cdot\left(\frac{\bar{C}}{\overline{Q(C)}}\right) \\
& =\left(0.708-0.045^{*} 13.491\right) *(5635755 / 2497487)=0.228 \\
15 \quad & \varepsilon_{Q R}=\frac{\partial Q(R)}{\partial R} \cdot \frac{R}{Q(R)}=\left(\alpha_{R}+\alpha_{P R} \bar{P}\right) \cdot\left(\frac{\bar{R}}{\overline{Q(R)}}\right) \\
= & \left(-210214.4+16199.46^{*} 13.491\right) *(65.121 / 2497487)=-0.217
\end{aligned}
$$


The parameter giving the impact of the second investigation $\left(\lambda_{2}\right)$ is studied in the second and third models. In both models, its value is also found negative indicating that the second investigation has also a positive effect on competition. However, in both models, this effect is not statistically significant at any meaningful significance level, as shown by rather large $p$-values. The affect of the third investigation is examined only in the third model. The relevant parameter $\left(\lambda_{3}\right)$ is found negative and significantly different from zero. It means that, in contrast to the second investigation, the third investigation contributed positively to the level of competition in the cement market.

Table 4

2SLS Regression Estimates for Supply Relation (8)

\begin{tabular}{|c|c|c|c|c|c|c|}
\hline \multirow[b]{2}{*}{ Parameter } & \multicolumn{2}{|c|}{$\begin{array}{c}\text { Model } 1 \\
\lambda=\lambda_{0}+\lambda_{1} D 1997\end{array}$} & \multicolumn{2}{|c|}{$\begin{array}{c}\text { Model } 2 \\
\lambda=\lambda_{0}+\lambda_{1} D 1997 \\
+\lambda_{2} D 2000\end{array}$} & \multicolumn{2}{|c|}{$\begin{array}{c}\text { Model 3 } \\
\lambda=\lambda_{0}+\lambda_{1} D 1997+ \\
\lambda_{2} D 2000+\lambda_{3} D 2003\end{array}$} \\
\hline & Estimate & p-value & Estimate & p-value & Estimate & p-value \\
\hline Intercept $\left(\beta_{0}\right)$ & $\begin{array}{c}4.353422 \\
(1.102552)\end{array}$ & 0.000 & $\begin{array}{c}4.333282 \\
(1.116068)\end{array}$ & 0.000 & $\begin{array}{c}5.360405 \\
(1.208508)\end{array}$ & 0.000 \\
\hline $\begin{array}{l}\text { Quantity of } \\
\text { cement }\left(\beta_{Q}\right)\end{array}$ & $\begin{array}{c}4.88 \mathrm{e}-07 \\
(1.48 \mathrm{e}-07)\end{array}$ & 0.001 & $\begin{array}{c}4.92 \mathrm{e}-07 \\
(1.52 \mathrm{e}-07)\end{array}$ & 0.002 & $\begin{array}{c}5.51 \mathrm{e}-07 \\
(1.53 \mathrm{e}-07)\end{array}$ & 0.000 \\
\hline $\begin{array}{l}\text { Real price of } \\
\text { electricity }\left(\beta_{E}\right)\end{array}$ & $\begin{array}{c}0.0569809 \\
(0.0382018)\end{array}$ & 0.138 & $\begin{array}{c}0.0577245 \\
(0.0387141)\end{array}$ & 0.138 & $\begin{array}{c}0.0382117 \\
(0.0394792)\end{array}$ & 0.335 \\
\hline $\begin{array}{l}\text { Real price of pit } \\
\text { coal }\left(\beta_{M}\right)\end{array}$ & $\begin{array}{c}0.0004902 \\
(0.0000455)\end{array}$ & 0.000 & $\begin{array}{c}0.0004902 \\
(0.0000457)\end{array}$ & 0.000 & $\begin{array}{c}0.0004448 \\
(0.0000501)\end{array}$ & 0.000 \\
\hline$\lambda_{0}$ & $\begin{array}{c}0.0338492 \\
(0.0083193)\end{array}$ & 0.000 & $\begin{array}{c}0.0340308 \\
(0.0084501)\end{array}$ & 0.000 & $\begin{array}{c}0.0347155 \\
(0.0083846)\end{array}$ & 0.000 \\
\hline$\lambda_{1}$ & $\begin{array}{c}-0.0411241 \\
(0.0089947)\end{array}$ & 0.000 & $\begin{array}{l}-0.0406385 \\
(0.0096504)\end{array}$ & 0.000 & $\begin{array}{l}-0.0391725 \\
(0.0095934)\end{array}$ & 0.000 \\
\hline$\lambda_{2}$ & - & - & $\begin{array}{l}-0.0014442 \\
(0.0100963)\end{array}$ & 0.886 & $\begin{array}{l}-0.0025339 \\
(0.0100237)\end{array}$ & 0.801 \\
\hline$\lambda_{3}$ & - & - & - & - & $\begin{array}{l}-0.1053473 \\
(0.0498415)\end{array}$ & 0.037 \\
\hline $\mathrm{R}^{2}$ & 0.524 & & 0.523 & & 0.535 & \\
\hline
\end{tabular}

Notes: Standard errors in parentheses.

Source: authors' computations according to equation (8).

At this point, it should be noted that the calculated parameters $\lambda_{1}, \lambda_{2}$ and $\lambda_{3}$ provide us information regarding only marginal contributions of the investigations on the current competition level. To evaluate the intensity of competition in the periods between investigations, the hypotheses that the relevant sum of these parameters are equal to 0 (price taking behaviour) should be tested. For this aim, for the period between December 1997 and March $2000 H_{0}: \lambda_{0}+\lambda_{1}=0$, for the period between March 2000 and March $2003 H_{0}: \lambda_{0}+\lambda_{1}+\lambda_{2}=0$, and for the period between March 2003 and 
December $2004 H_{0}: \lambda_{0}+\lambda_{1}+\lambda_{2}+\lambda_{3}=0$ tests were conducted. The results show that although the predicted value of $\lambda_{0}+\lambda_{1}$ is negative, $H_{0}: \lambda_{0}+\lambda_{1}=0$ can-not be rejected at the $5 \%$ significance level, indicating a price taking behaviour during the period between December 1997 and March 2000. Similarly, in spite of a negative predictions for $\lambda_{0}+\lambda_{1}+\lambda_{2}$ and $\lambda_{0}+\lambda_{1}+\lambda_{2}+\lambda_{3}, H_{0}: \lambda_{0}+\lambda_{1}+\lambda_{2}=0$ and $H_{0}: \lambda_{0}+\lambda_{1}+\lambda_{2}+\lambda_{3}=0$ cannot be rejected for the period between March 2000 and March 2003, and March 2003 and December 2004 at 5\% and 1\% significance levels implying that price taking behavior continues.

It may be possible to compare our results with those of Kulaksizoglu (2004), the only study carrying similar goals to ours. Three alternative models in our study clearly demonstrated that the level of the competition intensity at the period prior to first investigation, namely the end of year 1997, cannot be defined as perfect competition. During this period in which no competition law was applicable, the cement producers as a whole enjoyed some degree of market power. For this early period, the results of Kulaksizoglu (2004) are consistent with ours. Our study also witnessed that the investigations initiated by the Turkish Competition Authority made the market more and more competitive. Especially first investigation started in 1997 had a significant effect on the degree of competition in the cement market. For the period following the first investigation and on, according to all three alternative models in our study, the hypothesis that the cement producers acted as price takers cannot be rejected at any meaningful significance level. On the other hand, Kulaksizoglu (2004) estimated that the introduction of competition law in 1997 did not have any positive effect on the degree of market power in the cement market. The reason for this inconsistency between two studies using the same Bresnahan-Lau framework may be several. First, the number of observations, their coverage and frequency are different: As we used 132 monthly data covering between January 1994 and December 2004, Kulaksizoglu (2004) used 17 yearly data spanning the period between 1986 and 2002. Second, while in Kulaksizoglu (2004) the conduct parameter includes only one dummy variable for the year 1997, monthly observations in our data set allows us to examine separately the effects of the each investigation in years 1997, 2000 and 2003. Thus, it may be claimed that our finding that the introduction of competition law and the investigations carried out by Competition Board have made the cement market more competitive is more reliable.

\section{Conclusion}

The main goal of this study was to assess the likely effects of the introduction of competition law in Turkey on the cement market. As soon as it started to function in 1997, the Turkish Competition Board initiated several investigations on the cement producers. At the beginning, our initial expectation was surely that these investigations supported with a lot of human and financial sources had an effect of increasing the degree of competition in the market. On the other hand, we were aware of the fact that, since the very beginning, the Competition Board has still important handicaps, which may decrease its efficiency significantly. First, investigation procedures arranged in the Turkish Competition Act are rather long. The Board can take its decisions regarding infringements within two years approximately. Also, according to the Turkish 
Competition Act, once the parties went to the court (the State Council) to appeal the decision imposing fine, they did not have to pay the fine until the final decision of the court. Another drawback before the Board has been that the relation between the Board and the State Council has been always uneasy. In this study, we aimed to find an answer to the question whether the Competition Board managed to increase the intensity of competition in the cement market despite all these obstacles.

The results of this study are consistent with our initial expectations. Accordingly, the cement producers had a considerable amount of market power at the period prior to first investigation in December 1997. With the first investigation started in December 1997, the market shifted significantly to a more competitive environment. The positive effect of the first investigation on the level of competition in the cement market is very obvious, and this result is robust across alternative model specifications. The second and the third investigations also increased the competition in the market, although their marginal effects were not statistically significant. As a result, since the beginning of the first investigation and throughout the second and the third ones, the cement producers continued their price taking behaviors. However, this should be interpreted as only a sign of an increase in the degree of competition in the market, and does not necessarily mean that the cement market has been cleaned up from all collusive behaviors with the beginning of the competition law in Turkey. It is certainly true that the cement producers are now casting their account in a more competitive environment. However, once collusive behavior is found to be profitable by the managers of cement producers, they do not hesitate to meet in the proverbial smoke-filled rooms. For this reason, the cement market will unavoidably remain under scrutiny of the Competition Board.

\section{References}

Bask, M., Lundgren, J., Rudholm, N. (2009), "Market Power in the Expanding Nordic Power Market." Applied Economics, First published 19 August 2009 (iFirst).

Bresnahan, T. F. (1982), "The Oligopoly Solution Concept is Identified." Economic Letters, 10, pp. 87-92.

Buschena, D. E., Perloff, J. M. (1991), "The Creation of Dominant Firm Market Power in the Coconut Oil Export Market." American Journal of Agricultural Economics, 73, pp. 1000-1008.

Choi D., Philippatos, G. C. (1983), "Financial Consequences of Antitrust Enforcement", Review of Economics and Statistics, 65, pp. 501-6.

Çelen, A. (2003), "Measuring Degree of Competition in the U.K. Tea Market: a Dynamic Error Correction Approach." Rekabet Dergisi, 14, pp. 75-116 (in Turkish).

Deodhar, S. Y., Sheldon, I. M. (1997), "Market Power in the World Market for Soymeal Exports." Journal of Agricultural and Resource Economics, 22, pp. 78-86.

Dickey, D., Fuller, W. A. (1979), "Distribution of the Estimators for Autoregressive Time Series with a Unit Root." Journal of the American Statistical Association, 74, pp. 427-431.

Feinberg R.M. (1980), "Antitrust Enforcement and Subsequent Price Behaviour." Review of Economics and Statistics, 62, pp. 609-612.

Konings J., Cayseele, P. V., Warzynski, F. (2001), "The Dynamics of Industrial Mark-Ups in Two Small Open Economies: Does National Competition Policy Matter?" International Journal of Industrial Organization, 19, pp. 841-859. 
Kulaksizoglu, T. (2004), "Measuring the Effectiveness of Competition Policy: Evidence from the Turkish Cement Industry." Munich Personal RePEc Archive (MPRA) Paper No. 1092, http://mpra. ub.uni-muenchen.de/1092/.

Lau, L. J. (1982), "On Identifying the Degree of Competitiveness from Industry Price and Output Data." Economics Letters, 10, pp. 93-99.

Newmark, C. M. (1988), "Does Horizontal Price Fixing Raise Price? A Look at the Bakers of Washington Case." Journal of Law and Economics, 31, pp. 469-484.

Shaffer, S. (1993), "A Test of Competition in Canadian Banking." Journal of Money, Credit, and Banking, 25(1), pp. 49-60.

SPO (2008), Dokuzuncu Kalkınma Planı, 2007-2013: Taş ve Toprağa Dayalı Sanayiler Özel İhtisas Komisyonu Raporu. Ankara: State Planning Organization. http://www.dpt.gov.tr/DocObjects/ Download/3868/oik703-c1.pdf.

Sproul M. F. (1993), “Antitrust and Prices.” The Journal of Political Economy, 101(4), pp. 741-754.

Stigler G. J., Kindahl, J. (1970), The Behaviour of Industrial Prices. New York: Columbia University Press (for NBER).

Suominen, M. (1991), "Competition in Finnish Banking - Two Tests." Bank of Finland, Discussion Paper, No. 8/91.

Symeonidis G. (2002), "The Effects of Competition: Cartel Policy and the Evolution of Strategy and Structure in British Industry." MIT Press.

Whish, R. (2001), "New Economy, Old Competition Policy?" Paper presented at The Second Annual Conference on the Impact of Globalisation and New Technology on Competition, Competition Commission of South Africa, Lynwood Ridge, South Africa, 29-30 March, 2001.

Zeidan R. M., Resende, M. (2009), "Measuring Market Conduct in the Brazilian Cement Industry: A Dynamic Econometric Investigation." Review of Industrial Organization, 34, pp. 231-244. 